\title{
Bile acid diarrhea as the leading symptom of misplacement of a biliary stent into the colon
}

Biliocolonic fistulas are usually associated with severe clinical symptoms including recurrent cholangitis, sepsis, and abdominal pain $[1,2]$. To the best of our knowledge, this is the first case in which misplacement of a biliary stent was associated with a mild clinical course, bile acid diarrhea being the leading symptom.

A 76-year-old man was admitted to another hospital with an acute abdomen in October 2009. A perforating cholecystitis with gallstone ileus was diagnosed, and cholecystectomy and a Billroth II resection of the stomach were performed. The postoperative course was complicated by sepsis and, as a consequence of the inflammatory process in the upper part of the abdomen, a fibrotic stenosis of the common bile duct (CBD) developed.

The patient was transferred to our hospital for further management of cholestasis. Endoscopic retrograde cholangiopancreatography (ERCP) with stent placement was attempted but unsuccessful. After a timeconsuming and technically challenging procedure, a self-expanding nitinol stent was implanted into the CBD via a percutaneous transhepatic approach on 5 February 2010 . A cholangiography immediately after the procedure was interpreted as showing free drainage of the contrast material into the duodenum. The patient was discharged from hospital.

During the following 6 months the patient suffered from chronic watery diarrhea, lost $10 \mathrm{~kg}$ in weight, but had no other symptoms. On 16 August 2010, he was admitted to our hospital for evaluation of chronic diarrhea. A computed tomography (CT) scan demonstrated aerobilia and the nitinol stent draining from the CBD into the hepatic flexure of the colon (๑ Fig. 1a,b).

Colonoscopy showed the distal $0.5 \mathrm{~mm}$ of the stent extending into the colon, but was otherwise normal $(\bullet$ Fig. 2).

Retrospective evaluation of the radiological images revealed that the misplacement of the stent into the colon had been visible immediately after the insertion of the stent ( $\bullet$ Fig. 3 and $\mathbf{4}$ ).
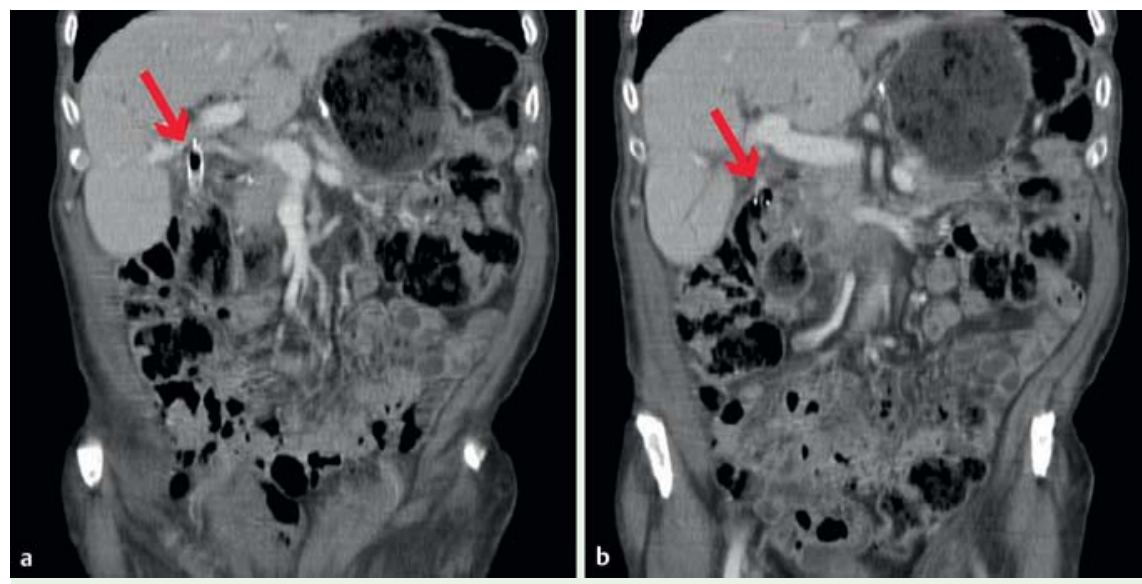

Fig. 1 Computed tomography (CT) scan: a the proximal end of the nitinol stent is visible in the common bile duct (arrow); $\mathbf{b}$ the distal end of the nitinol stent is located in the hepatic flexure of the colon (arrow).

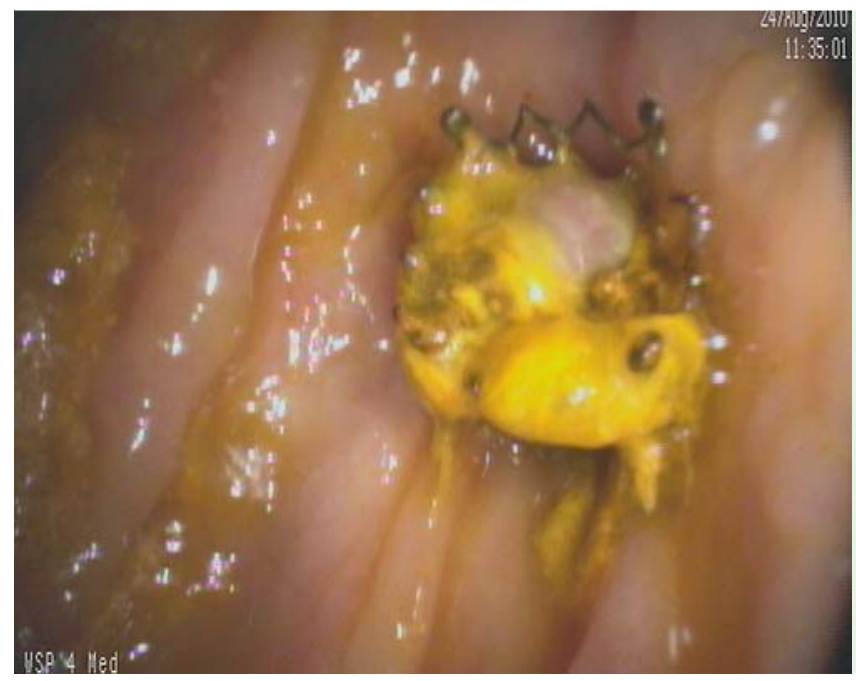

Fig. 2 Colonoscopy showing the distal $0.5 \mathrm{~mm}$ of the stent extending into the colon.

The nitinol stent was removed surgically and a choledochoduodenostomy was performed. At 6-month follow-up the patient was asymptomatic; the watery diarrhea had stopped completely after the operation.

This case demonstrates that biliocolonic fistulas do not always cause severe complications. In our patient, over a period of 6 months, watery diarrhea was the leading symptom of misplacement of the biliary stent into the colon. After exclusion of other etiologies, this watery diarrhea had to be interpreted as bile acid diarrhea.The diarrhea showed prompt resolution after surgical restoration of biliary drainage into the duodenum [3].
Endoscopy_UCTN_Code_CPL_1AK_2AD

Competing interests: None 

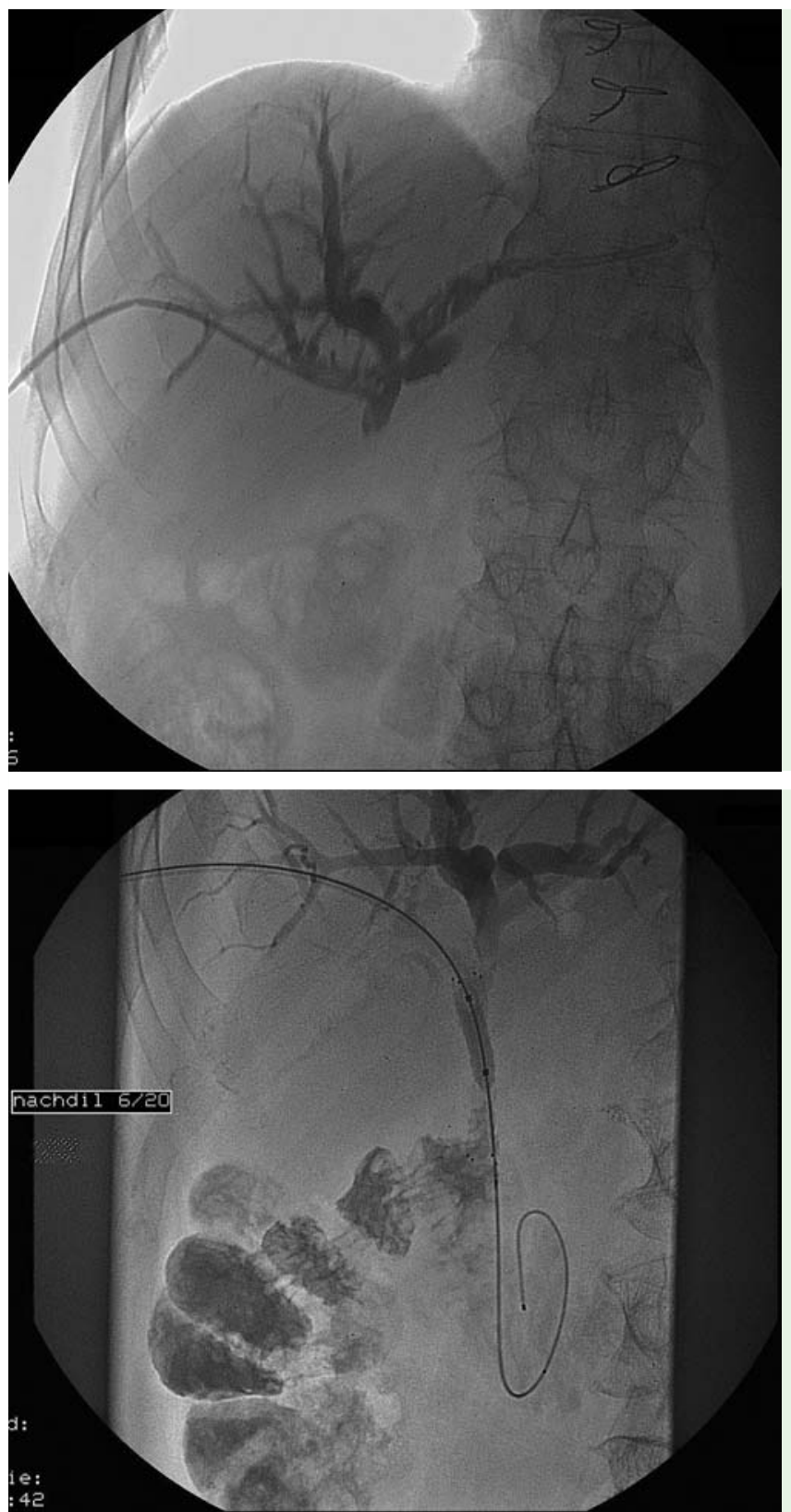

Fig. 3 Percutaneous transhepatic cholangiography demonstrating dilation of intrahepatic bile ducts. Because of a fibrotic stenosis of the distal part of the common bile duct, there is no drainage of contrast material into the duodenum.

Fig. 4 After a timeconsuming and technically challenging procedure, a self-expanding nitinol stent was implanted into the common bile duct. Retrospectively, it is evident that the stent was misplaced into the hepatic flexure of the colon.

\section{G. Dworschak ${ }^{1}$ E. Dulic-Lakovic ${ }^{1}$,} M. Dulic ${ }^{1}$, C. Neumann², K. Glaser ${ }^{3}$, A. Holzäpfel ${ }^{1}$, M. Gschwantler ${ }^{1}$ 1 4th Department of Internal Medicine, Wilhelminenspital, Vienna, Austria

2 Department of Radiology, Wilhelminenspital, Vienna, Austria

3 Department of Surgery, Wilhelminenspital, Vienna, Austria

\section{References}

1 Güitrón-Cantú A, Adalid-Martínez R, Barinagarrementeria-Aldatz $R$ et al. Choledochocolonic fistula secondary to primary choledocholithiasis. Gastrointest Endosc 2001; 54: 227

2 Munene G, Graham JA, Holt RW et al. Biliarycolonic fistula: a case report and literature review. Am Surg 2006; 72: 347 - 350

3 Fan X, Sellin JH. Review article: small intestinal bacterial overgrowth, bile acid malabsorption and gluten intolerance as possible causes of chronic watery diarrhoea. Aliment Pharmacol Ther 2009; 29: 1069-1077

\section{Bibliography}

DOI $10.1055 / \mathrm{s}-0030-1256787$

Endoscopy 2011; 43: E338 -E339

(c) Georg Thieme Verlag KG Stuttgart · New York . ISSN 0013-726X

\section{Corresponding author}

\section{Gschwantler, MD}

Wilhelminenspital

4th Department of Internal Medicine

Montleartstrasse 37

A-1160 Vienna

Austria

Fax: 43-1-49150-2409

michael.gschwantler@wienkav.at 